\title{
THE IMPACTS OF FRIENDSHIP, ADVICE AND NEGATIVE TIES ON INTENTION TO LEAVE: THE CASE OF NURSES IN A SPECIAL BRANCH HOSPITAL
}

\author{
Cenk Sozen', Simge Samanci2, Ismail Tokmak3, Hakan Turgut3, Nejat Basim' \\ 1. Faculty of Economics and Administrative Sciences, Baskent University, Ankara, Turkey \\ 2. Vocational School of Health Services, Hacettepe University, Ankara, Turkey \\ 3. Faculty of Fine Arts, Design and Architecture, Program of Gastronomy and Culinary Arts, Baskent University, Ankara, Turkey
} Correspondence: simge_atakli@hacettepe.edu.tr

\section{ABSTRACT}

\section{OBJECTIVES}

The high turnover rate of nurses has been a matter of debate among scholars. Nurses' social interaction patterns and the social structure they are situated within may provide clues about possible causes of their high turnover intentions. This study aims to investigate the possible effects of negative and positive ties on the intention of turnover among nurses.

\section{DESIGN \& SETTING}

A hybrid research methodology was used. Social network analysis was used to reveal the positions of the nurses ( $\mathrm{n}=126$ ) in the positive and negative networks. A statistical model was formed with varying types of centrality measures, intragroup conflict, and intention to leave variables. The data was collected from all the nurses working in a special branch hospital.

\section{RESULTS AND CONCLUSION}

The findings of the study clearly indicate that negative interactions directly and indirectly affect the intention to leave, and the nurses demand professional support from their colleagues. The findings also show the existence of a fragmented social structure among nurses, which suggests the increased importance of brokerage roles.

Managers should closely monitor the negative interactions among nurses, and they need to use conflict management techniques frequently to reduce hostile relations in the business environment. Managers should especially seek ways to increase altruistic tendencies among colleagues because nurses demand professional support ties more than friendship relations.

\section{KEYWORDS}

Social network theory, turnover rate, intention to leave, positive ties, negative ties, intragroup conflict. 
Inpatient care services can be considered as one of the most salient characteristics of the hospitals when compared to all other health care organizations. Therefore, quality of nursing care plays a critical role in terms of organizational performance in hospitals. Despite their vital importance, nurses have considerably high rates of turnover, which Lagerlund et al. [1] defines as a global problem. The relevant literature highlights various negative impacts of having high nurse turnover rates on hospitals [210]. High turnover rate also signals high level of nurse mobility in the health care field, which may lead to inefficiency regarding the costs of employee recruitment, training, and orientation. There has been a significant number of empirical research efforts to reveal the causes of nurses' excessive turnover intention [11-16]. The findings have signified multi causal explanations ranging from job dissatisfaction, burnout, inappropriate leadership styles to the lack of professional autonomy, medication errors, and low social status. Most of these studies are based on individual responses of nurses towards certain statements in behavioral scales. Therefore, we believe these variables should be examined in conjunction with the social structure where the nurses are embedded in.

Nurses have social interactions with their colleagues and other clinical and administrative staff in hospitals. Nurses' social interaction patterns and the social structure they are situated within may provide clues about possible causes of their high furnover intentions. There has been an increasing trend in management and organization studies to understand how social interaction patterns impact dynamics in business life [17-34] but most of the network researchers have been concerned with the positive interactions among actors, such as those based on friendship, partnership and acquaintanceship. It is not inconceivable that positive ties among individuals in the workplace could somehow contribute to the positive organizational climate. However, negative ties which are based on dislike, hostility, jealousy, envy and rivalry among individuals may lead to more significant behavioral outcomes than positive ties. The importance of negative networks was emphasized by important scholars $[35,36]$ and the impacts of negative ties on various popular issues such as job satisfaction, organizational attachment and emergence of conflicts were examined by a series of studies [37-41]. The findings suggest that the patterns of positive and negative interactions among employees 


\section{1- TURNOVER INTENTION, NURSING CARE AND THE HEALTH SECTOR}

Turnover intention is defined as the key factor explaining employees' decisions to leave an organization [44, 45]. Therefore, high turnover intention represents a tendency of an actor to quit his/her job. There are various definitions of turnover intention in the relevant literature. For example, seeking for alternative job possibilities in other organizations [46], having perceptions of individuals to leave their current position [47] and negative emotions towards sustaining organizational membership [48] are some well-known definitions. Turnover intention may not suddenly trigger an actual turnover decision, but it may cause multiple undesirable psychological, sociological and economic consequences for employees [49]. It is not possible to expect positive performance outcomes from an employee having an intention to quit his/her job as it is pointed out by Battistelli et al. [50]. The possible causes of turnover intention will be discussed later but it is worth mentioning here that there are two paradigms in the literature. A group of authors [44] claim that some behavioral variables determine turnover intention while others [51,52] believe in the significance of social relations in the workplace. The question of whether the individual or contextual factors determine turnover intention is an important problem deserving empirical and theoretical efforts.

Hospitals rely on nursing care more than other health care organizations. Quality of nursing care directly affects discharge rates, and determines the efficiency of inpatient units. Hence, high turnover rate in this occupational group is more important than those in any other sectors. When nurses leave hospitals, quality of patient care drastically suffers [7-10, 53, 54]. Direct and indirect costs may emerge because of high nursing turnover rates in hospitals resulting from several reasons [55]. First of all, it may lead to an unstable work environment for the others [56]. Secondly, loss of members can prevent proper teamwork $[4,8,57]$ and each resignation leads to extra time and resources for the new recruits $[10,14,58,59]$. And finally, valuable human and intellectual capital of the health care institution are sacrificed [60]. These are the micro consequences of high nursing turnover intention, but this problem has also become increasingly important in parallel with ageing world population due to incremental needs for high quality nursing care $[1,61]$.
There is a significant number of empirical studies in the management literature which aim at examining the causes of turnover intention not only in the groups of nurses but also all in other types of occupational groups. Arnold and Feldman [62] classify the factors affecting turnover intention into five categories. These are macroeconomic factors (i.e. economic status of the country, characteristics of the labor market, etc.), organizational factors (i.e. size, HR policies, management or leadership style, etc.), individual job attitudes (i.e. satisfaction, citizenship, stress, commitment), demographic variables (i.e. age, marital status, education, sex, etc.), and non-work related factors such as family. In the relevant literature there are many findings specifically concerning the factors affecting turnover intention of the nurses. Some of the authors claim that organizational burnout, uncivil behavior and workplace bullying are among the main causes affecting not only the current staff but also the newcomer nurses [63, 64]. Tomietto et al. [65] highlight the influence of problematic socialization process for the newcomer nurses in parallel with these arguments. A group of researchers [66-68] state that occupational tenure and marital status are also critical variables that determine turnover intention because findings indicate young and single nurses are generally have higher turnover rates. The other causes of high turnover intention of the nurses are high physical demand of the job [69], work stress [14, 70-72], lack of professional autonomy because of the centralized structure [1, 14, 73-76], physician-nurse conflicts [4], role stres [77], and lack of professional respect [78]. The empirical findings suggest a complex and multidimensional view of high turnover intention problem of the nurses.

There are also studies underlining more contextual aspects of this problem. The type of hospitals may have an influence on turnover intention because teaching and research hospitals are characterized by low turnover rates than the others [79]. Opportunities to do research in this type of health care institutions may somehow contribute to nurses' self-actualization and professional recognition. Societal and organizational culture may also play a critical role in terms of turnover intention. Comprehensive studies in Korea indicate that strong organizational culture is positively associated with job satisfaction and negatively associated with intention to leave [80-82]. That seems quite normal in Eastern countries characterized by collective societal behavior but validity of these findings is quite suspicious in Western cultures having pragmatic and individualistic features. High turnover rates in hospitals can 
cause an extra burden for the remaining nursing staff, which may sooner or later result in resignations [66]. Therefore, it is possible to state that inevitable increase of nursing turnover in the health care sector may cause a vicious cycle.

Turnover researchers imply that the decision to leave a job is a combination of workplace interactions, working conditions and psycho-social factors [83]. Some of the findings remind that establishing a positive organizational climate in inpatient care services may help overcome the triggering effect of multiple variables on turnover intention. Research evidence indicates that nurses seek social support, cohesive relations and a helpful socia environment in their workplaces [52, 65, 80-82, 84]. However, social relations may also lead to controversial outcomes such as dysfunctional conflicts, deviant workplace behaviors and job dissatisfaction. Negative networks, which can be denoted as antimatter of positive networks, may lead to various unanticipated consequences in the workplaces. Stress, workload and other factors may also trigger employees' strained reactions to each other. This may create a social environment, which is suitable for the emergence of negative ties among nurses. It is also important to find out whether the nurses who have dyadic negative interactions can behave unprejudiced to each other in their professional networks such as advice. The positions of opponents and the patterns of their friends' mutual interactions in friendship networks may also provide critical information for the high nurse turnover rate problem. Nurses demand social support from their colleagues and look for an amiable work environment according to the relevant literature. Therefore, a close examination of the ongoing arguments in social network theory may help to define positive and negative aspects of the social structure.

\section{2- POSITIVE VERSUS NEGATIVE WORKPLACE RELATIONS}

The findings concerning turnover intention of the nurses' state that a positive organizational climate might be helpful to reduce negative impacts of multiple factors. High internal social capital, which is characterized by strong positive ties among organizational participants, could be very helpful to create an atmosphere of mutual trust and a peaceful work environment [17, 20, 85]. Development of strong ties requires incremental frequency of interactions between parties during the course of time [24, 86] and actors should spend extra effort to preserve their strong ties. On the contrary, negative ties may suddenly emerge in a work group and can easily devastate a positive social environment. A considerable number of scholars claim that studying negative networks is more important than the positive networks because of various reasons [36, 39-41, 87 , 88]. Negative ties increase actors' awareness and focus concerning the social structure, in other words actors who have negative ties with others start to cognitively evaluate ongoing relations in the workplace $[41,89]$. Actors who are involved in dyadic negative relations generally seek supporters to gain power against their opponents [35] and this may cause rapid spread of hostile feelings into the social environment. Negative networks usually have lower densities than positive networks but their social impacts are much more influential $[90,91]$. When actors experience negative interactions in their workplace they prefer to stay away as far as possible from the actors who are involved in such a relationship [35, 91]. This response of the actors' towards negative interactions makes it impossible to create an atmosphere of trust and increase social cohesiveness in a workplace.

There are also structural causes of negative relations among actors. A social structure, which is rich in terms of structural holes, may lead to the emergence of different types of negative relations. Ronald Burt considers the brokers, who are acting as bridges between unconnected parts of the social system, as the key actors having various advantages such as being able to reach valuable information, adjust knowledge or set barriers for undesired flow of critical information [19, 92-94]. However, all the structural power gained through brokerage positions is only valid for positive networks. Most of the network researchers haven't predicted the impact of brokers on negative interactions among actors in a fragmented social structure. Labianca et al. [36] highlight that the actors' unawareness about each other can increase the possibility of mutual negative interactions and brokers may have amplifying effects in this respect. Therefore, it is important to observe whether there are brokers between the actors and groups having negative relations in a workplace.

Employees may develop negative feelings towards others because of various reasons in the workplace but they may also hesitate to establish negative relations with some of the actors having special roles and positions in an organization or work group. Status distribution in groups is determined based on the formal power, members' contributions to the group goals, and personal characteristics [95]. Recent studies highlight that individuals are less likely to have negative relations with higher status 
group members [96]. Managers, successful or popular employees can be regarded as actors having high status in the workplaces. There might be exceptional situations but it seems logical for the employees to have good relations with these actors.

\section{3- A MODEL CONCERNING THE IMPACTS OF PROFESSIONAL, FRIENDSHIP AND NEGATIVE TIES ON TURNOVER INTENTION OF THE NURSES}

A considerable number of researchers highlight that positive workplace relations can help reduce the impact of other factors such as stress, burnout, problematic personality and dysfunctional conflict on the employees' tendency to leave their jobs [97]. A positive organizational climate is especially important for the nurses trying to deal with unhappy patients and their relatives in a stressful work environment [52, 65, 80-82, 84]. In this study, we intended to examine how negative, friendship and advice professional relations - interactions among nurses affect their turnover intention. It is important to study the reactions of the nurses towards negative and positive social interactions with their colleagues because a deep analysis of the social structure where nurses embedded in might give us clues about interactional causes of high turnover intention.

We assume that advice and friendship relations are positive ties and negative attitudes of the nurses towards each other are negative ties. The positions of the actors in advice, friendship and negative networks has been comparatively analyzed in an influential article [41]. In this study, we try to explore whether the positions of the actors in these three different types of networks have direct or indirect effects on turnover intention of nurses. Various types of centrality measures, which are indicated in Figure 1, may positively or negatively be associated with intragroup conflict and this in turn may affect intention to leave or these network variables might have a direct impact on the dependent variable -intention to leave.

\section{FIGURE 1: RESEARCH MODEL}

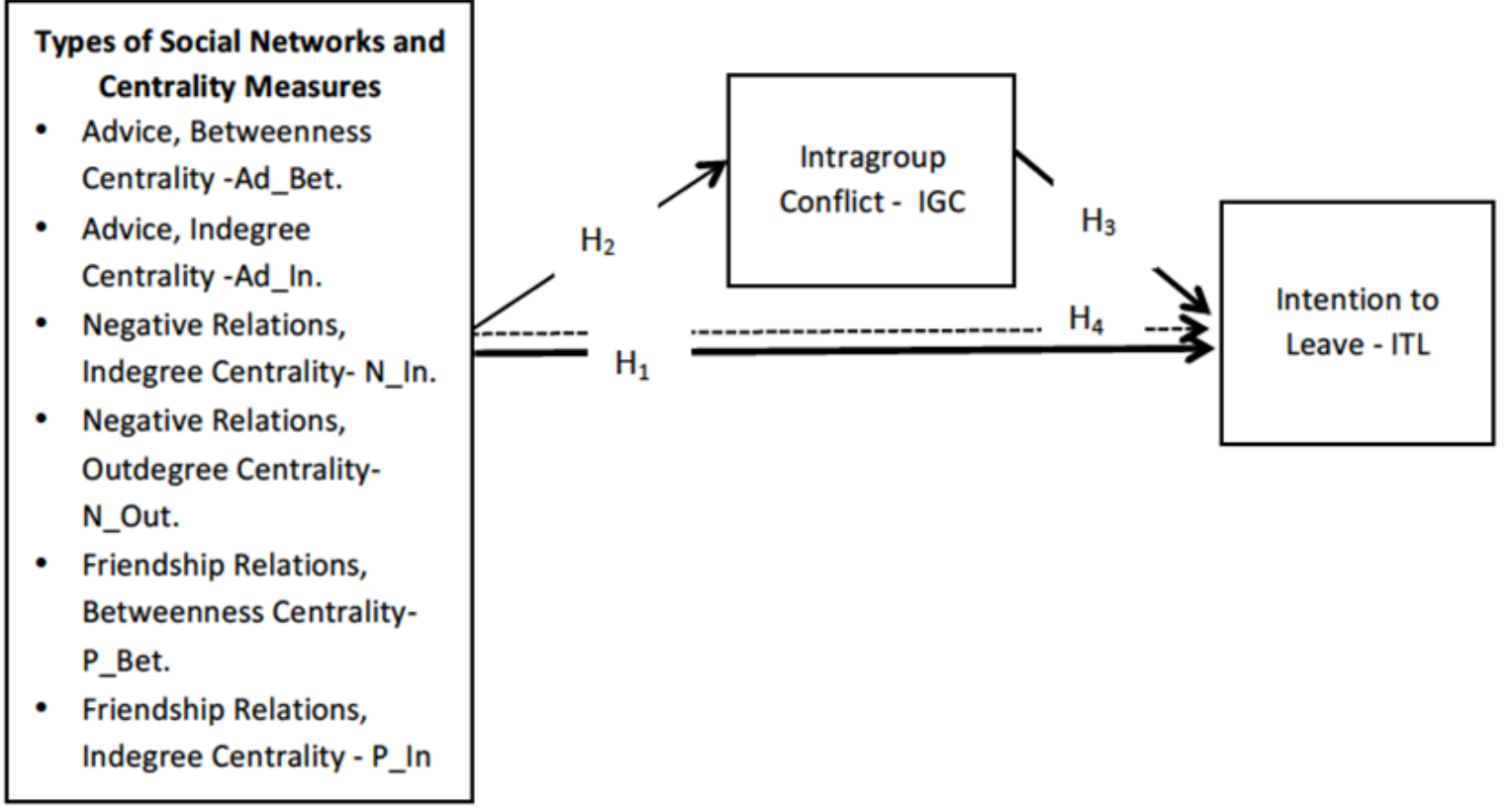

We have decided to apply the centrality measures betweenness and degree-, which might affect the level of conflict among nurses and their intention to leave. Therefore, a series of hypothesis were generated to investigate the potential effect of actors' networking behavior on their basic attitudes and possible work-related actions.

The positive ties that contribute to social cohesiveness and satisfaction gained from professional relations in the workplace may directly impact the tendency of nurses to quit their jobs. Numerous negative interactions with colleagues may prevent emergence of a desirable work environment for a focal actor.

H1: Positions of actors in friendship, advice and negative networks affect intention to leave.

Hla: Betweenness centrality in advice networks is negatively associated with intention to leave.

H1b: Indegree centrality in advice networks is negatively associated with intention to leave.

H1c: Indegree centrality in negative networks is positively associated with intention to leave. 
H1d: Outdegree centrality in negative networks is positively associated with intention to leave.

H1e: Betweenness centrality in friendship networks is negatively associated with intention to leave.

HIf: Indegree centrality in friendship networks is negatively associated with intention to leave.

Having mediator roles or relatively more direct connections with the colleagues in the positive networks may decrease the possibility of conflict emergence. The most disliked individuals in the negative networks may inevitably face various types of conflict cases because of their problematic relations in the workplace. It is important to determine whether certain features of social networks lead to intragroup conflict.

H2: Positions of the actors in friendship, advice and negative networks affect intragroup conflict.

H2a: Betweenness centrality in advice networks is negatively associated with intragroup conflict.

H2b: Indegree centrality in advice networks is negatively associated with intragroup conflict.

H2c: Indegree centrality in negative networks is positively associated with intragroup conflict.

H2d: Outdegree centrality in negative networks is positively associated with intragroup conflict.

H2e: Betweenness centrality in friendship networks is negatively associated with intragroup conflict.

H2f: Indegree centrality in friendship networks is negatively associated with intragroup conflict.

The extant literature highlights that conflict is not necessarily associated with the negative outcomes such as burnout, demotivation, and job dissatisfaction. Functional conflict may positively affect some of the well-known dependent variables in OB. It is important to determine whether positions of the actors in positive and negative networks lead to dysfunctional conflict, which may increase the tendency of employees to quit. Therefore, searching the mediator role of intragroup conflict between network centrality and intention to leave can help us to understand the role of multiple types of social interactions in this respect.

H3: Intragroup conflict is positively associated with intention to leave.

H4: Intragroup conflict has a mediator role in the relationship between centrality in friendship, advice and negative networks, and intention to leave.

H4a: Intragroup conflict has a mediator role in the relationship between intention to leave and betweenness centrality in advice networks.
H4b: Intragroup conflict has a mediator role in the relationship between indegree centrality and intention to leave in advice networks.

H4c: Intragroup conflict has a mediator role in the relationship between intention to leave and indegree centrality in negative networks.

H4d: Intragroup conflict has a mediator role in the relationship between intention to leave and outdegree centrality in negative networks.

H4e: Intragroup conflict has a mediator role in the relationship between intention to leave and betweenness centrality in friendship networks.

H4f: Intragroup conflict has a mediator role in the relationship between intention to leave and indegree centrality in friendship networks.

\section{METHODOLOGY}

This study was conducted on 126 nurses working in a special branch hospital located in a metropolitan area. Our research team applied formally to several hospitals and only few of them returned back. The sample characteristic of the special branch hospital seemed to be the most appropriate one. Table 1 indicates sample characteristics of the study. The descriptive statistics concerning gender, age, marital status and professional experience are given below. A great majority of the respondents are between 18 and 43 years old. The nurses in the research coverage have considerable levels of professional experience. $78.5 \%$ of the nurses are female, $21.4 \%$ are male; $37.3 \%$ are married and a great majority of them are single $-62.7 \%$.

TABLE 1: SAMPLE CHARACTERISTICS

\begin{tabular}{lll}
\hline Characteristic & N & \% \\
\hline Gender & 99 & 78.57 \\
Female & 27 & 21.43 \\
Male & & \\
\hline Age (Year) & 51 & 40.48 \\
$18-30$ & 57 & 45.24 \\
$31-43$ & 18 & 14.28 \\
$44>$ & & \\
\hline Marital status & 47 & 37.30 \\
Married & 79 & 62.70 \\
Single & & \\
Professional experience (year) & 97 & 76.98 \\
\hline $10 \geq$ & 29 & 23.02 \\
$10<$ & 126 & 100 \\
\hline Total & & \\
\hline
\end{tabular}


A group of researchers had gathered both social network data and they used turnover intention and intragroup conflict scales during the face-to-face meetings with the respondents. Three different questions were asked to the respondents to determine their advice, friendship and negative ties with the others. A list of all the nurses working in the healthcare facility was formed and distributed to all the interviewers with the questionnaire forms including scales. It was requested from each respondent to denote the names of the nurses according to the three questions, which have been used frequently used to determine friendship, advice and negative ties in the relevant literature [36, 41, 98, 99]. These three questions are:

Friendship Relations: Do you consider this person to be a close friend?

Advice Ties: Do you go to this person for work related advice and knowledge?

Negative Ties: Sometimes people at work make us feel uncomfortable or uneasy and, therefore, we try to avoid interacting with them. Do you avoid interacting with this person? Yes/no.

The turnover intention scale, which was developed by Cammann et al. [100] was used in this study. That scale was adapted to the local culture by Gurbuz and Bekmezci [101]. Rahim [102] developed ROCl-I in 1983. The scale was adapted by Kocaman et al. [103]. It was initially aimed to determine indegree and betweenness centrality scores of the actors in positive networks - friendship and advice. These two centrality measures may lead to different consequences in a social structure because indegree shows influential actors in terms of incoming direct ties and betweenness shows how many times a focal actor occupies positions between two actors who don't have direct connections in a network. The relevant literature highlights that most of the centrality analyses don't work in negative networks. In a negative network it is not possible to have an information flow among nodes. Therefore, applying measurement items such as closeness, betweenness and eigenvector centrality to the negative networks seem to be useless [90]. However, degree centrality for asymmetric networks may show the most disliked individuals (i.e. indegree), and a focal actor's negative perception about the others (i.e. outdegree). Thus, we decided to use indegree and outdegree centrality measures in negative networks.

UCINET program was used to analyze the data concerning the positive - advice, friendship - and the negative networks. The centrality scores of each actor were put into model with the data concerning intragroup conflict and intention to leave scales. SmartPLS was used for all types of statistical analyses. Validity and reliability studies were conducted before running the model. Internal consistency reliability, convergent validity and discriminant validity tests were applied to the data. Cronbach's alpha and composite reliability (CR) coefficients were examined for internal consistency reliability. Factor loads and AVE (average variance extracted) values were used to determine convergent validity of the scales. It was expected to have $\geq 0.70$ for the factor loads and cronbach alpha and AVE values should be over $\geq 0.50$ [104-106]. The results are indicated in Table 2.

TABLE 2: FINDINGS OF THE MEASUREMENT MODEL

\begin{tabular}{|c|c|c|c|c|c|}
\hline Variable & $\begin{array}{l}\text { Factor } \\
\text { load }\end{array}$ & $\begin{array}{l}\text { Cronb } \\
\text { ach } \\
\text { Alfa }\end{array}$ & $\begin{array}{l}\text { rho_ } \\
\text { A }\end{array}$ & CR & AVE \\
\hline Ad_Bet & 1,000 & 1,000 & 1,000 & 1,000 & 1,000 \\
\hline Ad_In & 1,000 & 1,000 & 1,000 & 1,000 & 1,000 \\
\hline N_In & 1,000 & 1,000 & 1,000 & 1,000 & 1,000 \\
\hline N_Out & 1,000 & 1,000 & 1,000 & 1,000 & 1,000 \\
\hline F_Bet & 1,000 & 1,000 & 1,000 & 1,000 & 1,000 \\
\hline F_In & 1,000 & 1,000 & 1,000 & 1,000 & 1,000 \\
\hline \multirow{3}{*}{$\begin{array}{l}\text { Intention to } \\
\text { Leave }\end{array}$} & 0,882 & \multirow{3}{*}{0,896} & \multirow{3}{*}{0,897} & \multirow{3}{*}{0,935} & \multirow{3}{*}{0,828} \\
\hline & 0,925 & & & & \\
\hline & 0,922 & & & & \\
\hline \multirow{5}{*}{$\begin{array}{l}\text { Intragroup } \\
\text { Conflict }\end{array}$} & 0,773 & \multirow{5}{*}{0,846} & \multirow{5}{*}{0,855} & \multirow{5}{*}{0,892} & \multirow{5}{*}{0,627} \\
\hline & 0,795 & & & & \\
\hline & 0,889 & & & & \\
\hline & 0,867 & & & & \\
\hline & 0,605 & & & & \\
\hline
\end{tabular}

Abbreviation: Ad, advice network; N, negative network; F, friendship network; In, indegree; Out, outdegree; Bet, betweenness.

Hair et al. [106] state that if factor loads are below $\geq 0.708$; a) the items which are below 0,40 should directly be removed from the model, b) the items having values between $0.40-0.70$ should be removed from the model if AVE or CR values are below then the edge value. Accordingly, items 1,5 and 8 were removed from the model. The remaining items in the scale were reanalyzed and even though item 7 had a factor load value below .708 -.605- was kept in the model because AVE and CR values were above the edge values. It can be concluded that the scales have internal consistency reliability, because Cronbach's Alpha coefficients are between 0.892 - 1.000 and rho A coefficients are between 0.895 - 1.000, CR coefficients are between 0.892 and 1.000. It is evident 
from the figures in Table 2 that the convergent validity was achieved because AVE values are between 0.627 -1.000 and the factor loads are 0.605 - 1.000. Cronbach Alpha, rho A and CR coefficients for social network centrality items -betweenness, indegree and outdegree values- were given value of 1 due to measurement by using single item.
Hetrotriat-Monotrait Ratio criterions - HTMT-, which was suggested by Henseler et al. [107] was used to determine discriminant validity. The authors highlight that more relevant concepts should theoretically be below 0.90 and less relevant concepts below 0.85. The HTMT values in Table 3 indicate that the research variables have discriminant validity.

TABLE 3: FINDINGS OF THE DISCRIMINANT VALIDITY ANALYSIS

\begin{tabular}{|l|l|l|l|l|l|l|l|l|}
\hline & Ad_Bet & Ad_In & $\begin{array}{l}\text { Intention } \\
\text { to Leave }\end{array}$ & $\begin{array}{l}\text { Intragroup } \\
\text { Conflict }\end{array}$ & N_In & N_Out & F_Bet & F_In \\
\hline Ad_Bet & & & & & & & & \\
\hline Ad_In & 0,483 & & & & & & & \\
\hline $\begin{array}{l}\text { Intention } \\
\text { to Leave }\end{array}$ & 0,038 & 0,048 & & & & & & \\
\hline $\begin{array}{l}\text { Intragrou } \\
\text { p Conflict }\end{array}$ & 0,256 & 0,240 & 0,351 & & & & & \\
\hline N_In & 0,238 & 0,151 & 0,404 & 0,267 & & & & \\
\hline N_Out & 0,110 & 0,103 & 0,045 & 0,149 & 0,074 & & & \\
\hline F_Bet & 0,439 & 0,290 & 0,020 & 0,289 & 0,070 & 0,210 & & \\
\hline F_In & 0,305 & 0,636 & 0,077 & 0,430 & 0,024 & 0,035 & 0,499 & \\
\hline
\end{tabular}

Abbreviation: Ad, advice network; N, negative network; F, friendship network; In, indegree; Out, outdegree; Bet, betweenness.

The centrality scores of the actors in friendship, advice and negative networks were put into the model together with the perception scores on their intention to leave and the level of intragroup conflict. Social network patterns were examined in detail and statistical tests were performed, because a hybrid research method was adopted in this research.

\section{FINDINGS}

A detailed analysis of the interaction patterns among nurses may provide useful clues concerning the social features of their workplace. Figure 2, 3 and 4 provide the diagrams representing friendship, advice and negative networks. The structural differences among these networks can simply be realized because each of them has a specific purpose. The two positive networks aim at satisfying socialization and professional needs of the organizational participants. On the contrary, negative relations indicate the actors' dislike or refraining from having any kind of a positive interaction.
Figure 4 shows professional relationships established by the nurses. The actors, who are effective in the friendship network, are not so influential in the advice network. When it comes to professional relationships among nurses, they may simply ignore their friends and look for the actors having experience and occupational knowledge. $x 1, x 9$, $X 12, X 16, X 20, X 109$ and X123 are the influential actors and some of them have managerial roles. Advice network is relatively less dense -0.33 - than the friendship network. Average degree is 4.49 , average distance is 3.19 and the diameter of network is 6 . When compared to the network consisting of friendship relations, the advice network is characterized by a loosely coupled structure having less complicated relations.

Negative networks are generally expected to have lower densities than the positive networks [90]. The negative network in Figure 4 has a density of 0.03 , which is significantly lower than the positive networks-friendship and advice. However, a core group of actors in the network have directional, reciprocal and indirect negative relations among themselves. There are also few dyadic and triadic 
negative interactions located far away from this main group. Existence of this group signifies a high conflict potential in the social structure. X12 and X14, who can be regarded as influential actors in the friendship and advice networks, also seem to have significant levels of negative interactions with their colleagues.
The structural equation model to test the hypotheses is given in Figure 5. The model consists of the different centrality scores of the actors in each network as independent variables, intragroup conflict as mediator variable and attitudes of the participants towards intention to leave as dependent variable.

\section{FIGURE 2: FRIENDSHIP NETWORK OF THE NURSES}

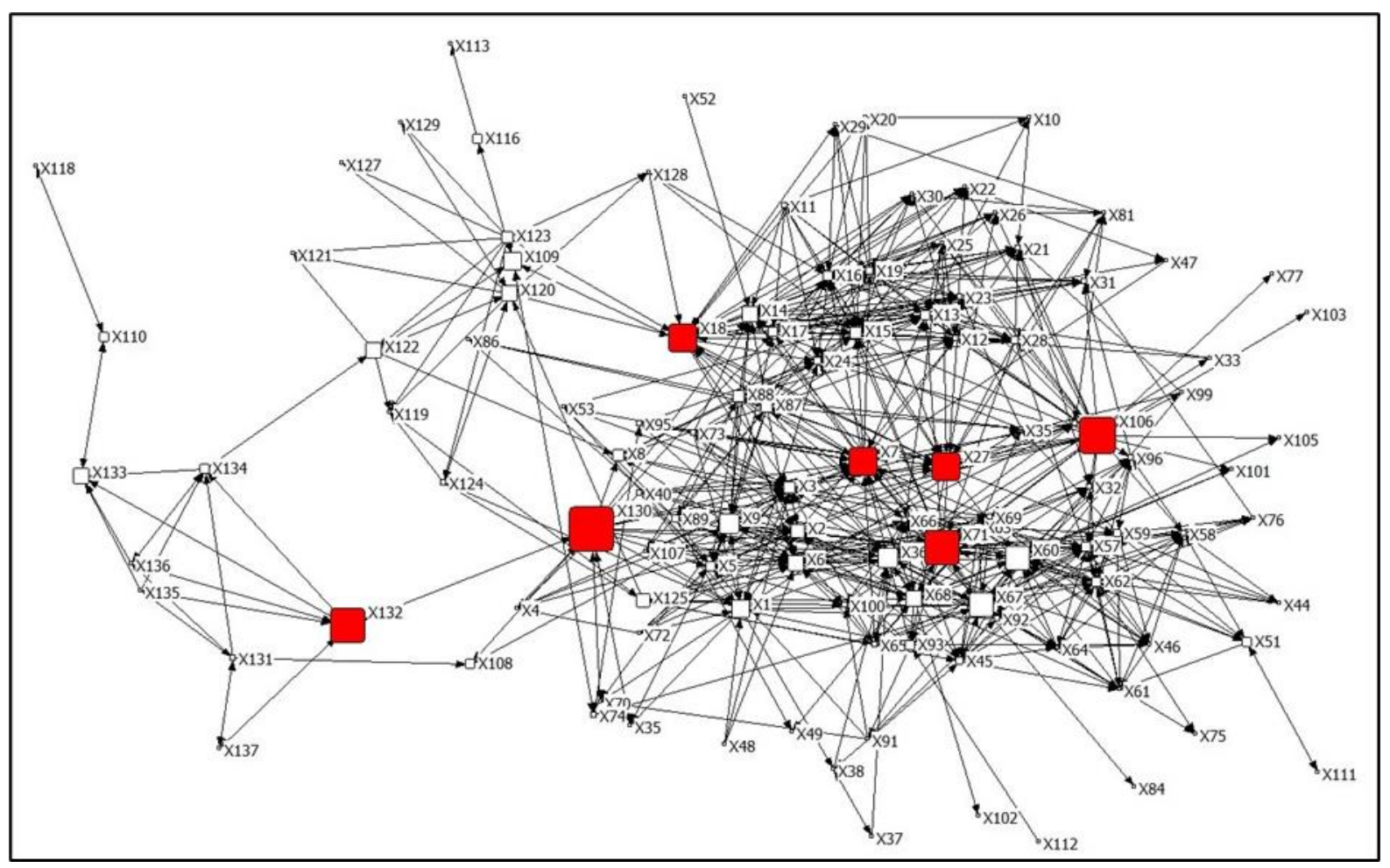

FIGURE 3: ADVICE NETWORK OF THE NURSES

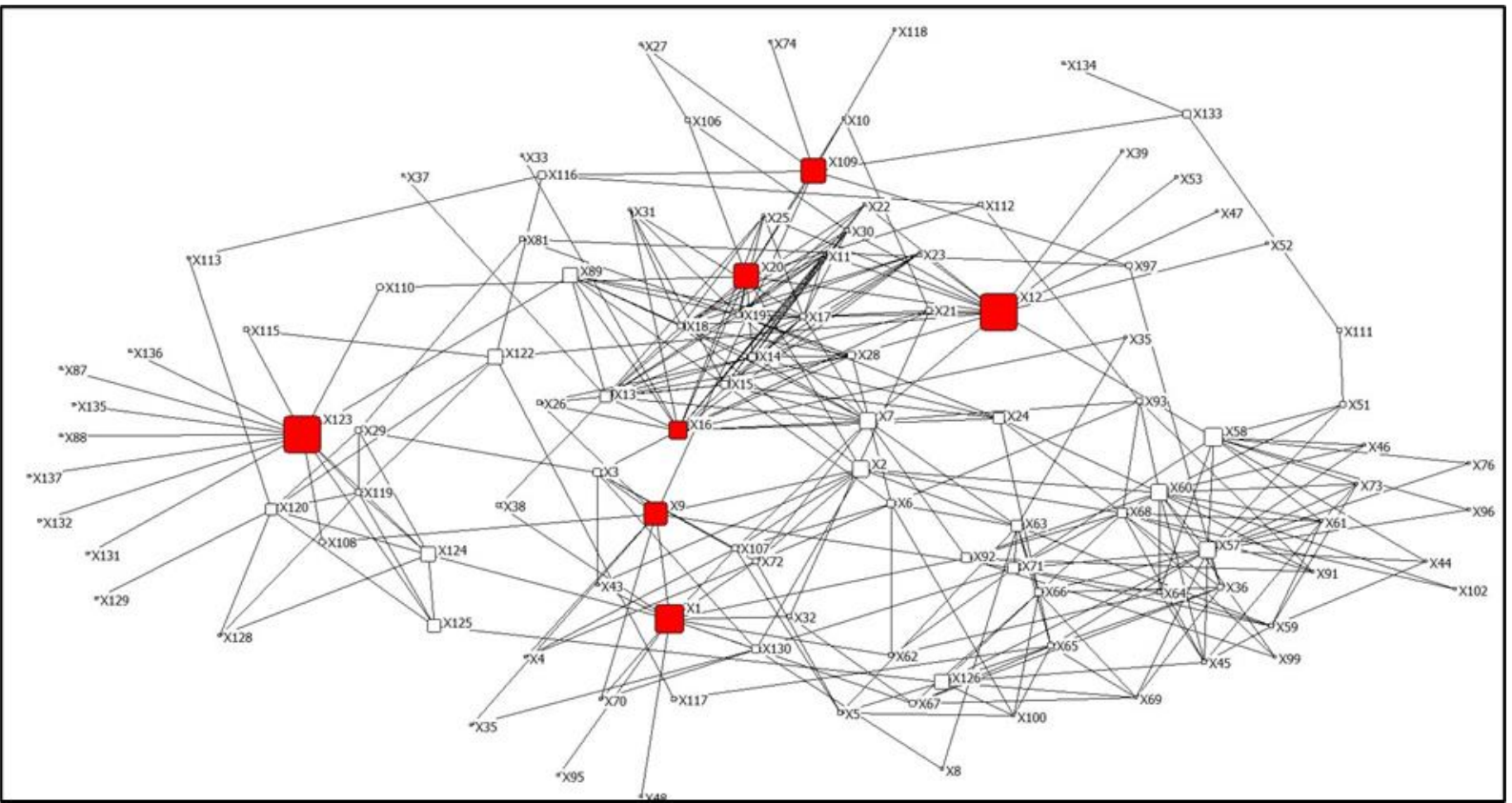




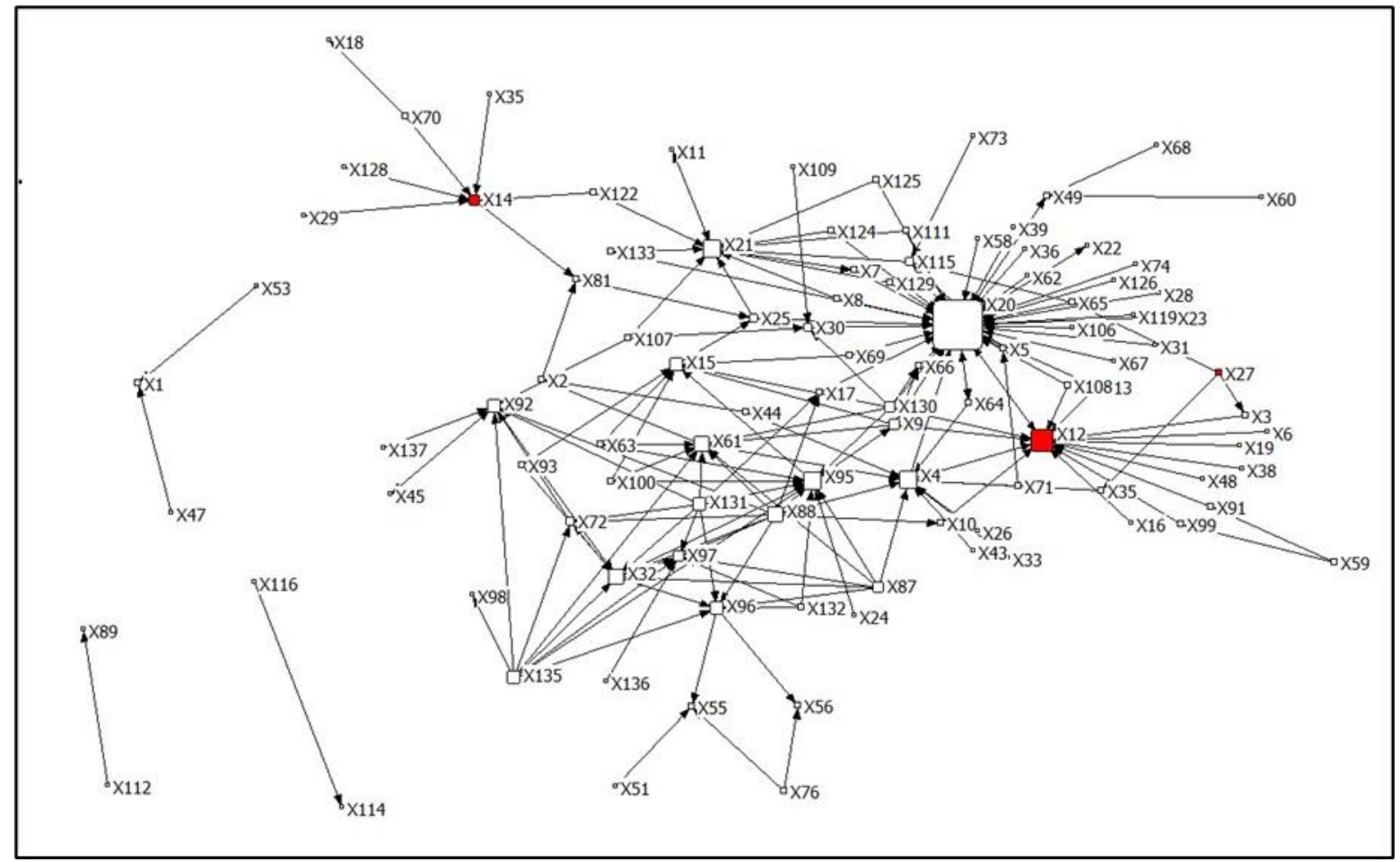

FIGURE 5: STRUCTURAL EQUATION MODEL

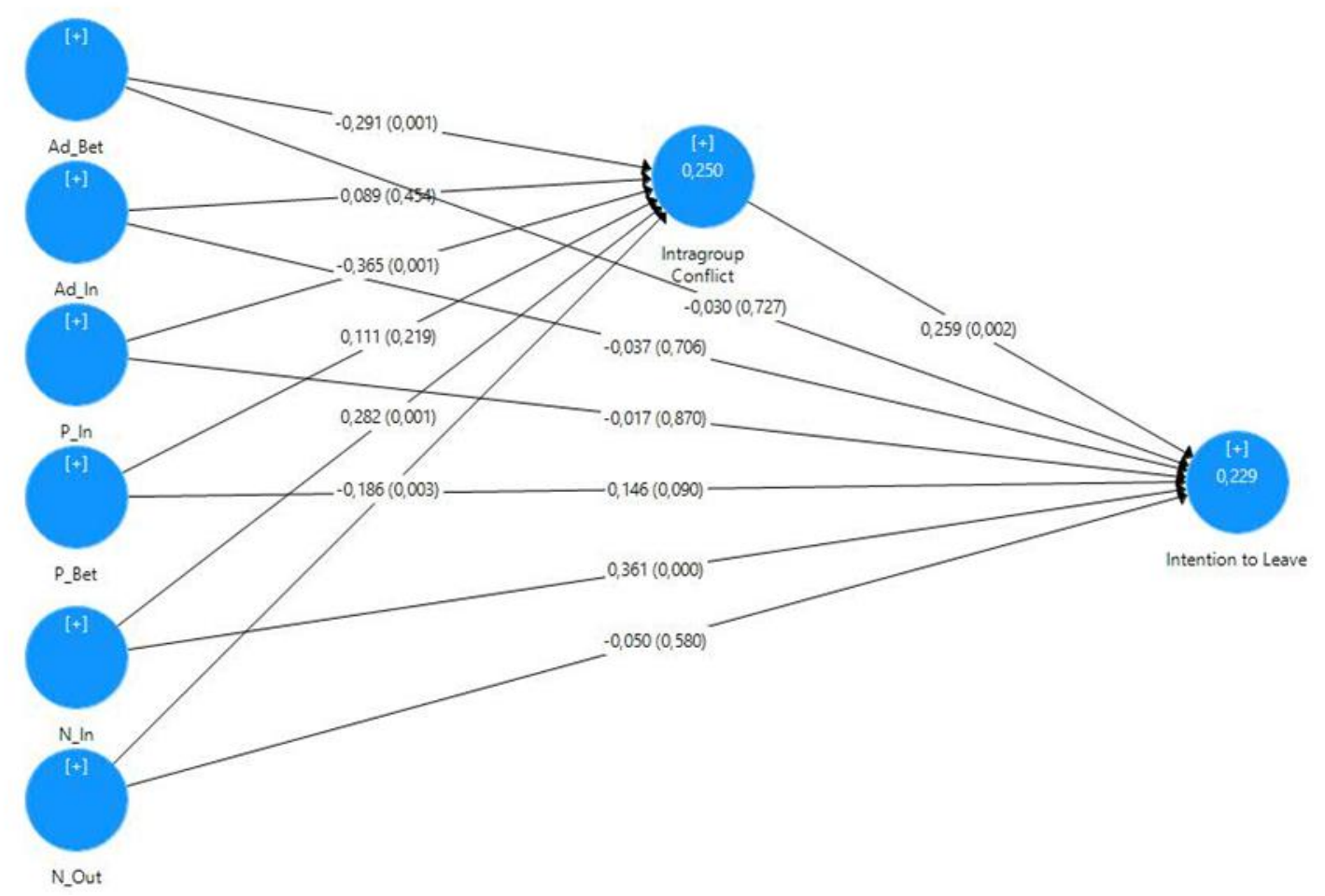

Partial least square equation modeling - PLS-SEM - was used calculate the prediction power - Q2. Bootstrapping method to test the research model. The data were analyzed with was applied and the t-values were calculated by taking SmartPLS - version 3.2.9 - program. PLS algorithm was used 5000 subsample from the main sample to evaluate to calculate linearity, path coefficients, R2 and the impact significance of PLS path coefficients. The VIF, R2 and Q2 scale (f2'); blindfolding analysis was conducted to values are presented in Table 4. 
TABLE 4: FINDINGS OF THE RESEARCH MODEL

\begin{tabular}{|c|c|c|c|c|}
\hline Variables & & VIF & $\mathbf{R}^{2}$ & $\mathbf{Q}^{2}$ \\
\hline Ad_Bet & \multirow{7}{*}{ Intragroup Conflict } & 1,743 & \multirow{7}{*}{0,29} & \multirow{7}{*}{0,161} \\
\hline Ad_In & & 2,169 & & \\
\hline F_ln & & 2,354 & & \\
\hline F_Bet & & 1,697 & & \\
\hline N_In & & 1,257 & & \\
\hline N_Out & & 1,131 & & \\
\hline Intragroup Conflict & & 1,385 & & \\
\hline Ad_Bet & \multirow{6}{*}{ Intention to Leave } & 1,658 & \multirow{6}{*}{0,21} & \multirow{6}{*}{0,157} \\
\hline Ad_In & & 2,161 & & \\
\hline F_ln & & 2,126 & & \\
\hline F_Bet & & 1,689 & & \\
\hline N_ln & & 1,121 & & \\
\hline N_Out & & 1,105 & & \\
\hline
\end{tabular}

Abbreviation: Ad, advice network; N, negative network; F, friendship network; In, indegree; Out, outdegree; Bet, betweenness.

TABLE 5: DIRECT IMPACT COEFFICIENTS OF THE RESEARCH MODEL

\begin{tabular}{|c|c|c|c|c|c|c|}
\hline Variables & & $\begin{array}{l}\text { Standardize } \\
\text { d } \beta\end{array}$ & $\begin{array}{l}\text { Standardiz } \\
\text { ed Error }\end{array}$ & t value & $\begin{array}{l}p \\
\text { value }\end{array}$ & $\begin{array}{l}\text { Confidence } \\
\text { Interval (\%95) }\end{array}$ \\
\hline Ad_Bet & \multirow{6}{*}{$\begin{array}{l}\text { Intention to } \\
\text { Leave }\end{array}$} & $-0,104$ & 0,091 & 1,138 & 0,255 & $-0,264 ; 0,091$ \\
\hline Ad_In & & $-0,013$ & 0,100 & 0,133 & 0,894 & $-0,211 ; 0,181$ \\
\hline F_ln & & $-0,107$ & 0,098 & 1,090 & 0,276 & $-0,289 ; 0,095$ \\
\hline F_Bet & & $-0,172$ & 0,089 & 1,926 & 0,046 & 0,$000 ; 0,351$ \\
\hline N_In & & 0,438 & 0,095 & 4,621 & 0,000 & 0,$248 ; 0,627$ \\
\hline N_Out & & $-0,098$ & 0,094 & 1,039 & 0,299 & $-0,284 ; 0,073$ \\
\hline Ad_Bet & \multirow{6}{*}{$\begin{array}{l}\text { Intragroup } \\
\text { Conflict }\end{array}$} & $-0,291$ & 0,088 & 3,315 & 0,001 & $-0,458 ;-0,112$ \\
\hline Ad_In & & 0,089 & 0,119 & 0,748 & 0,454 & $-0,151 ; 0,320$ \\
\hline F_ln & & $-0,365$ & 0,112 & 3,268 & 0,001 & $-0,584 ;-0,140$ \\
\hline F_Bet & & 0,111 & 0,090 & 1,230 & 0,219 & $-0,056 ; 0,300$ \\
\hline N_In & & 0,282 & 0,087 & 3,243 & 0,001 & 0,$115 ; 0,462$ \\
\hline N_Out & & $-0,186$ & 0,063 & 2,937 & 0,003 & $-0,317 ;-0,068$ \\
\hline $\begin{array}{l}\text { Intragroup } \\
\text { Conflict }\end{array}$ & $\begin{array}{l}\text { Intention to } \\
\text { Leave }\end{array}$ & 0,259 & 0,085 & 3,038 & 0,002 & 0,$093 ; 0,423$ \\
\hline
\end{tabular}

Abbreviation: Ad, advice network; N, negative network; F, friendship networ; In, indegree; Out, outdegree; Bet, betweenness. 
TABLE 6: INDIRECT IMPACT COEFFICIENTS OF THE RESEARCH MODEL

\begin{tabular}{|c|c|c|c|c|c|c|c|}
\hline \multicolumn{3}{|c|}{ Variables } & $\begin{array}{l}\text { Standardize } \\
\text { d B }\end{array}$ & $\begin{array}{l}\text { Standardize } \\
\text { d Error }\end{array}$ & $\begin{array}{l}t \\
\text { value }\end{array}$ & $\begin{array}{l}p \\
\text { value }\end{array}$ & $\begin{array}{l}\text { Confidence } \\
\text { Interval }\end{array}$ \\
\hline Ad_Bet & \multirow{6}{*}{$\begin{array}{l}\text { Intragroup } \\
\text { Conflict }\end{array}$} & \multirow{6}{*}{$\begin{array}{l}\text { Intention } \\
\text { to Leave }\end{array}$} & $-0,075$ & 0,036 & 2,082 & 0,037 & $-0,155 ;-0,017$ \\
\hline Ad_In & & & 0,023 & 0,036 & 0,644 & 0,520 & $-0,035 ; 0,108$ \\
\hline F_In & & & $-0,094$ & 0,048 & 1,970 & 0,049 & $-0,205 ;-0,021$ \\
\hline F_Bet & & & 0,029 & 0,027 & 1,054 & 0,292 & $-0,013 ; 0,094$ \\
\hline N_In & & & 0,073 & 0,032 & 2,249 & 0,025 & 0,$021 ; 0,147$ \\
\hline N_Out & & & $-0,048$ & 0,023 & 2,089 & 0,037 & $-0,99 ;-0,011$ \\
\hline
\end{tabular}

Abbreviation: Ad, advice network; N, negative network; F, friendship network; In, indegree; Out, outdegree; Bet, betweenness.

The linearity problem doesn't exist because it was noticed that the values are less than 5 when variance inflation factor - VIF- among variables examined [106]. It was found that $21 \%$ of intragroup conflict and $29 \%$ of intention to leave variables were explained when R2 values examined. The research model has indigenous variables' prediction power because prediction power coefficients - Q2 - are above 0 [106]. Therefore, it can be concluded that the research model has the prediction power on intragroup conflict and intention to leave variables due to below 0 Q2 values in Table 5. Direct impact coefficients of the research model are presented in Table 5.

The mediator variable was taken out of the model at the initial step to test significance of path coefficients. It was observed that $F$ Bet $(\beta=0.172 ; p<0.05)$ and $N \ln (\beta=0.438$; $\mathrm{p}<0.01$ ) variables have significant and negative impact on intention to leave. It was also determined that Ad Bet, Ad In, $\mathrm{P}$ In and N Out variables haven't significant effects on intention to leave. The hypotheses $\mathrm{H}_{1 e}$ was accepted and $H_{l a}, H_{l b}, H_{l c}, H_{l d}$ ve $H_{1 f}$ were rejected according to these findings.

The significance of the path coefficients was tested after including the mediator variable to the model at the second step. It was found that Ad_Bet $(\beta=-0.291 ; p<0.01)$; $F_{-}$In $(\beta=$ $0.365 ; p<0.01) ; N \_$In $(\beta=0.282 ; p<0.01)$ and N_Out $(\beta=-0.186$ $p<0.01$ ) were positively associated with intragroup conflict and intragroup conflict had a significant effect on intention to leave $(\beta=0.259 ; \quad<<0.01)$. There weren't any significant relations between Ad In, $\mathrm{F}$ Bet in and intragroup conflict. Therefore, hypotheses $\mathrm{H}_{2 a}, \mathrm{H}_{2 c}, \mathrm{H}_{2 f}$ and $\mathrm{H}_{3}$ were supported and $\mathrm{H}_{2} \mathrm{~d}, \mathrm{H}_{2 \mathrm{~b}}$ and $\mathrm{H}_{2 \mathrm{e}}$ were rejected. Indirect impact coefficients of the research model are presented in Table 6.
It is evident from the findings that $A d \_B e t(\beta=-0.075 ; p<0.05)$; $F \_I n(\beta=-0.094 ; p<0.05) ; N \_I n(\beta=0.073 ; p<0.05)$ and N_Out $(\beta=-0.048 ; p<0.05)$ variables' indirect effects on intention to leave are significant, but Ad_In and F_Bet variables don't have any kind of indirect effects on intention to leave through intragroup conflict variable. Independent variables should have significant effects on the dependent variables to think about a mediator effect according to Baron and Kenny [108]. Besides that, independent variables should affect mediator variables and mediator variables should affect dependent variables when mediator variables are added to the model. On the contrary, Zhao et al. [109] claim that even there is no significant effect of independent variables on dependent variables; in case of a sequential and directional relation from independent variable to mediator variable, from mediator variable to dependent variable it is possible to think about a mediation effect. Thus, it is possible to state that there are mediator relations, because Ad_Bet, F_In, N_In and N_Out have indirect effects on intention to leave.

VAF - variance accounted for - values were calculated because mediator effect was determined [110]. VAF values are; Ad_Bet $\rightarrow$ intragroup conflict $\rightarrow$ on the path of intention to leave is $0.42, F_{-}$In $\rightarrow$ intragroup conflict $\rightarrow$ on the path of intention to leave is $0.47, \quad N \_I n \rightarrow$ intragroup conflict $\rightarrow$ on the path of intention to leave is 0.14 and N_Out $\rightarrow$ intragroup conflict $\rightarrow$ on the path of intention to leave is 0.39. It was found that intragroup conflict has a partial mediator role in the relationship between Ad_Bet, F_In, N_Out and intention to leave variables due to VAF values. There is not a significant mediation effect for $N_{-}$In $\rightarrow$ Intragroup Conflict $\rightarrow$ on the path of intention to leave because VAF values which are below 0,20 are generally considered as insignificant [110]. We found empirical support for $\mathrm{H}_{4 a}, \mathrm{H}_{4 d}$ and $\mathrm{H}_{4 f}$, but not for $\mathrm{H}_{4 b}, \mathrm{H}_{4 c}$ and $\mathrm{H}_{4 e}$. 
negative interactions among nurses, because brokers may have amplifying effects between unconnected parties

The research findings clearly indicate that having direct according to Labianca et al. [36].

negative relations with others in the workplace increase nurses' tendency to quit their jobs. The individuals having incoming direct negative links increase their intention to leave their job. It is also evident that negative interactions can increase intragroup conflict, which may result in numerous resignations. Some researchers [80-83] have already emphasized the possible effects of workplace interactions on turnover rates. However, none of the scholars has focused on the dark side of the relations among nurses. This study reveals the fact that some occupational groups such as nurses seek intimate workplace relations and whenever they experience negative interactions with others, they might become much more sensitive.

The possible effects of centrality in the two types of positive social networks - friendship and advice - on intention to leave were also examined in this study. The literature clearly indicates that nurses facing various unanticipated events in their daily work routines demand cohesive and altruistic social relations $[52,65,80,81,84]$. The findings of this research also support the claims on the importance of satisfying socialization needs of the nurses, but the relevant literature hasn't explained whether professional or friendship ties decrease their intention to leave. This study clearly shows that having professional ties might be more important than having friendship ties in terms of decreasing nursing turnover rates. Centrality in advice network has an indirect effect through intragroup conflict on the dependent variable. The amount of direct ties in the advice network doesn't have a relation and effect on intention to leave but the nurses who have mediator or brokerage roles (i.e. high betweenness centrality) tend to stay in their jobs. This simply means that the actors who fill the structural holes by building bridges between unconnected parts of the friendship networks gain more satisfaction from their professional interactions [19, 92-94]. The actors having brokerage relations in the advice networks involving professional relations among nurses seem to have more positive attitudes towards workplace and it is highly possible that they don't want to leave the hospital. The fragmented social structure in the advice and friendship networks - Figure 2 and 3 - seem to increase the role and influences of the actors acting as brokers or cut points. These brokers may also be responsible for the emergence of this fragmented social structure and that of

\section{DISCUSSION}

The intellectual efforts to reveal the causes of high nursing turnover rates have been centered on multiple individual and contextual factors such as economic status of the country, characteristics of the labor market, HR policies, leadership styles, job satisfaction, organizational citizenship, stress, burnout, workplace bullying, orientation problems, occupational tenure, marital status, high physical demand, lack of autonomy and physician-nurse conflicts $[1,14,63$, $64,65,66,68,69,70,72,73,76,77,78]$. However, none of these studies have considered that most of these causes might be consequences of social interactions of the nurses in the workplaces. These individual and contextual factors may also shape the way an employee develops his/her relationships with others. Regardless of the ontological debate about this issue, examining the social networks of the nurses may provide significant clues that may bring practical insights to the problem of high nursing turnover and mobility. The claims of some scholars and research findings highlight the explanatory power of negative relations in organizations $[36,41,87,88,89]$. In parallel with the relevant literature, the findings of this study particularly support the significance of negative networks in terms of behavioral outcomes in organizations.

This study suggests an alternative viewpoint is required to understand and to solve the high turnover rates of the nurses. Increasing social solidarity may be a good option to overcome the impacts of negative ties but having friendly relations with colleagues doesn't contribute too much to the tendency of nurses to stay in the organization. It is quite rational to expect such a finding in the case of nurses because the existence of negative ties with the friendship relations can inevitably cause the emergence of rival groups. The actors who involve in mutual negative relations naturally rely on their friends and try to find out additional supporters [35, 41, 89]. This reaction will cause fragmentation of the social structure and may increase intergroup negative relations and conflict. The findings signify that those positive relations in the form of mentoring, consultation, or professional support instead of friendship may have a more significant effect on the nurses. The literature highlights the occupational burden of the nursing business. Therefore, professional relations with colleagues in 
the workplace may help to cope with the challenges of being a nurse.

\section{PRACTICAL IMPLICATIONS FOR HEALTH CARE MANAGERS}

The findings of this study give important clues for possible managerial interventions to reduce the high turnover rates of the nurses. Managers should be aware of the level of possible negative interactions among nurses, and find out the degree of fragmentation of the social structure in which they operate. The ones who are at the center of the negative networks and isolated from the positive networks may have the highest possibility to quit their jobs. These actors have to be identified and the possible causes of negative ties should be examined in detail. The employees who will be assigned to administrative roles in nursing units must have sufficient knowledge about conflict management techniques. Moreover, it is possible to form a preferable organizational climate if HR units can find out the right methods to help nurses develop professional and friendly interactions.

A preferable organizational climate especially for the nurses should be isolated from hostile relations. High social solidarity is not necessarily required to persuade nurses not to resign. Management should find ways to increase the intensity and frequency of altruistic professional interactions among nurses. One way of achieving this is to give the task of mentoring to the tenured staff. The nurses who will act as mentors should also have brokerage positions in the friendship and advise networks. Shaping organizational culture by using slogans favoring intra-occupational cooperation is another way to promote these relations.

\section{ETHICS DECLARATIONS}

Funding: No external funding has been received for this study.

Conflict of interest: The authors declare that they have no conflict of interest.

Ethical approval: All procedures performed in this study involving human participants were in accordance with the ethical standards of the institutional and/or national research committee, and with the 1964 Helsinki declaration and its later amendments or comparable ethical standards. The study protocol was approved by the ethical review committee of $X$ Hospital (Approval no:2145). All participants read a statement that explained the purpose of the survey and provided written informed consent before participation in the study.

\section{Referemces}

1. Lagerlund $M$, Sharp $L$, Lindqvist $R$, Runesdotter $S$, Tishelman C. Intention to leave the workplace among nurses working with cancer patients in acute care hospitals in Sweden. Eur J Oncol Nurs. 2015;19(6):629637.

2. De Gieter, S, Hofmans J, Pepermans R. Revisiting the impact of job satisfaction and organizational commitment on nurse turnover intention: an individual differences analysis. Int J Nurs Stud. 201 1;48(12):15621569.

3. Gaddy T, Bechtel GA. Nonlicensed employee turnover in a long-term care facility. Health Care Superv. 1995;13:54-60.

4. Galletta M, Portoghese I, Battistelli A, Leiter MP. The roles of unit leadership and nurse-physician collaboration on nursing turnover intention. J Adv Nurs. 2013;69(8):1771-1784.

5. Jones CB, Havens DS, Thompson PA. Chief nursing officer retention and tunover: A crisis brewing? Results of a national survey. J Healthc Manag. 2008;53:89105.

6. Lee H, Kim MS, Yoon JA. Role of internal marketing, organizational commitment, and job stress in discerning the turnover intention of Korean nurses. Jpn J Nurs Sci. 2011 1;8(1):87-94.

7. Meterko M, Mohr DC, Young GJ. Teamwork culture and patient satisfaction in hospitals. Med Care. 2004;42:492-498.

8. Shields MA, Ward M. Improving nurse retention in the National Health Service in England: the impact of job satisfaction on intention to quit. J Health Econ. $2001 ; 20: 677-701$.

9. Shortell SM, Zimmerman JE, Rousseau DM, Gillies RR, Wagner DP, Draper EA, Knaus WA, Duffy J. The performance of intensive care units: does good management make a difference?. Med Care. 1994;32:508-525.

10. Yim HY, Seo HJ, Cho Y, Kim J. Mediating role of psychological capital in relationship between occupational stress and turnover intention among nurses at veterans administration hospitals in Korea. Asian Nurs Res, 2017;11(1):6-12. 
11. Choi JS, Kim KM. Job embeddedness factors as a predictor of turnover intention among infection control nurses in Korea. Am J Infect Control. 2015;43(11):1213-1217.

12. Feng D, Su S, Yang Y, Xia J, Su Y. Job satisfaction mediates subjective social status and turnover intention among Chinese nurses. Nurs Health Sci. $2017 ; 19(3): 388-392$

13. Flinkman M, Leino-Kilpi $H$, Salanterä S. Nurses' intention to leave the profession: integrative review. J Adv Nurs. 2010;66 (7):1422-1434.

14. Hayes LJ, O'Brien-Pallas L, Duffield C, Shamian J, Buchan J, Hughes F, Stone PW. Nurse turnover: A literature review. Int J Nurs Stud. 2006;43:237-263.

15. Nantsupawat A, Nantsupawat R, Kulnaviktikul W, McHugh MD. Relationship between nurse staffing levels and nurse outcomes in community hospitals, Thailand. Nurs Health Sci. 2015;17:112-118.

16. Yang $P$, Hung $C$, Chen $Y$. The impact of three nursing staffing models on nursing outcomes. J Adv Nurs. 2015;71:1847-1856.

17. Bourdieu P. Forms of capital. In: J. Richardson, ed. Handbook of Theory and Research for the Sociology of Education. New York, NY: Greenwood;1983.

18. Bueno E, Salmador PM, Rodriguez $\mathrm{O}$. The role of social capital in today's economy. J Intellect Cap. 2004;5(4):556-574.

19. Burt SR. Structural Holes: The social structure of competition. Harvard University Press; 1992.

20. Coleman JS. Social capital in the creation of human capital. Am J Sociol. 1988;94:95-120.

21. Gargiulo M, Benassi M. Traped in your own net? Network cohesion, structural holes, and the adaptation of social capital. Organ Sci. 2000; 11 (2):183-196.

22. Granovetter M. Strength of Weak Ties. Am J Sociol. 1973;78:1360-1380.

23. Gulati R. Alliances and networks. Strateg Manag J. 1998;19(4):293-317.

24. Gulati R, Gargulio M. Where do interorganizational networks come from?. Am J Sociol. 1999;104(5):14391493.

25. Hammond CS, Glenn ML. The ancient practice of chinese social networking: Guanxi and social network theory. Emergence. 2004;6(1-2):24-31.
26. Hazleton V, Kennan W. Social capital: reconceptualizing the botttom line. Corp Commun. 2000;5(2):81- 86.

27. Kilduff GJ. Interfirm relational rivalry: implications for competitive strategy. Acad Manag Rev. 2019;44(4):775-799.

28. Kilduff GJ, Elfenbein HA, Staw BM. The psychology of rivalry: a relationally dependent analysis of competition. Acad Manage J, 2010;53(5):943-969.

29. Kostova T, Roth K. Social capital in multinational corporations and a micro-macro model of its formation. Acad Manag Rev. 2003;29(2):297-317.

30. Leana RC, Buren VHJ. Organizational social capital and employment practices. Acad Manag Rev. 1999;24(3):538- 555.

31. Paxton P. Is social capital declining in the United States? A multiple indicator assessment. Am J Sociol. $1999 ; 105(1): 88-127$.

32. Tsai W, Ghosal S. Social capital and value creation: The role of interfirm networks. Acad Manage J, $1998 ; 41(4): 454-476$.

33. Van De Ven HA. On the nature, formation and maintenance of relations among organizations. Acad Manag Rev. 1976;1 (4):24-36.

34. Westphal JD, Gulati R, Shortell MS. Customization or conformity? an institutional and network perspective on the content and consequences of TQM adoption. Adm Sci Q. 1997;42:366-394.

35. Labianca G, Brass DJ. Exploring the social ledger: Negative relationships and negative asymmetry in social networks in organizations. Acad Manag Rev. 2006;31 (3):596-614.

36. Labianca G, Brass DJ, Gray B. Social networks and perceptions of intergroup conflict: The role of negative relationships and third parties. Acad Manage J. 1998;41(1):55-67.

37. Ellwardt L, Labianca GJ, Wittek R. Who are the objects of positive and negative gossip at work?: a social network perspective on workplace gossip. Soc Networks. 2012;34(2): 193-205.

38. Grosser TJ, Sterling CM, Scott KD, Labianca G. Social networks, groups, and social exclusion: Combining sociometric and psychometric approaches to understanding social exclusion in organizational settings. In: CA Schriesheim, LL Neider, ed. The "Dark" Side of Management: Research in Management. Charlotte, NC: Information Age; 2010. 
39. Oldroyd J, Hendron M, Labianca G. Peacemaking at a price: The performance effects of brokering negative affect relationships. In: Paper presentation at the Intra-Organizational Networks Conference, Lexington, KY: 2008.

40. Venkataramani V, Dalal RS. Who helps and harms whom? relational antecedents of interpersonal helping and harming in organizations. J Appl Psychol. 2007;92(4):952-966.

41. Venkataramani V, Labianca GL, Grosser T. Positive and negative workplace relationships, social satisfaction, and organizational attachment. J Appl Psychol. 2013;98(6):1028-1039.

42. Schulte M, Ostroff C, Shmulyian S, Kinicki A. Organizational climate configurations: Relationships to collective attitudes, customer satisfaction, and financial performance. J Appl Psychol. 2009;94(3):618634.

43. Vandenberghe C, Bentein K, Michon R, Chebat JC, Tremblay M, Fils JF. An examination of the role of perceived support and employee commitment in employee-customer encounters. J Appl Psychol. 2007;92(4):1177-1187.

44. Egan TM, Yang B, Bartlett KR. The Effects of Organizational Learning Culture and Job Satisfaction on Motivation to Transfer Learning and Turnover Intention. Hum Resour Dev Q. 2004;15(3):279-301.

45. LV Q, Xu S, Ji H. Emotional labor strategies, emotional exhaustion, and turnover intention: An empirical study of Chinese hotel employees. J Hum Resour Hospit Tourism. 2012;1 1 (2):87-105.

46. Arshadi N, Damiri $H$. The relationship of job stress with turnover intention and job performance: Moderating role of OBSE. Procedia Soc Behav Sci. 2013;84:706-710.

47. Liou SR, Cheng CY. Organisational climate, organisational commitment and intention to leave amongst hospital nurses in Taiwan. J Clin Nurs. 2010;19(11-12):1635-1644.

48. Tett R, Meyer J. Job satisfaction, organizational commitment, turnover intention and turnover: path analyses based on meta-analytic findings. Pers Psychol. 1993;46:259-293.

49. Elci M, Erdilek MK, Alpkan L, Sener I. The mediating role of mobbing on the relationship between organizational silence and turnover intention. Procedia Soc Behav Sci. 2014;150:455-464.
50. Battistelli AA, Portoghese II, Galletta MM, Pohl SS. Beyond the tradition: Test of an integrative conceptual model on nurse turnover. Int Nurs Rev. 2013;60:103-111.

51. De Cuyper N, Mauno S, Kinnunen U, Mäkikangas A. The role of job resources in the relation between perceived employability and turnover intention: A prospective two-sample study. J Vocat Behav. $2011 ; 78(2): 253-263$.

52. Mossholder KW, Settoon RP, Henagan SC. A relational perspective on turnover: examining structural, attitudinal and behavioral predictors. Acad Manage J. 2005:48:607-618

53. Duffield C, Roche M, O'Brien-Pallas L, Diers DK, Aisbet† C, Aisbett K, Homer C. Nursing workload and staffing: Impact on patients and staff. In: University of Technology. Sydney:2009.

54. O'Brien-Pallas L, Murphy GT, Shamian J, Li X, Hayes LJ. Impact and determinants of nurse turnover: a panCanadian study. J Nurs Manag. 2010;18(8):1073-1086.

55. KUO HT, Lin KC, Li IC. The mediating effects of job satisfaction on turnover intention for long-term care nurses in Taiwan. J Nurs Manag. 2014;22(2):225-233.

56. O'Brien-Pallas L, Murphy GT, Shamian J. Understanding the costs and outcomes of nurses' turnover in Canadian hospitals. In: Canadian Institutes of Health Research. 2008.

57. Lankshear AJ, Sheldon TA, Maynard A. Nurse staffing and healthcare outcomes: a systematic review of the international research evidence. Adv Nurs Sci. 2005;28:163-174.

58. Contino DS. How to slash costly turnover. J Nurs Manag. 2002;33(2):10-13.

59. Waldman JD, Kelly F, Arora S, Smith HL. The shocking cost of turnover in health care. Health Care Manage Rev. 2004;29(1):2-7.

60. Dess G, Shaw J. Voluntary turnover, social capital, and organizational performance. Acad Manage Rev. $2001 ; 26(3): 446-456$.

61. Schalk D, Bijl M, Halfens R, Hollands L, Cummings $G$. Interventions aimed at improving the nursing work environment: a systematic review. Implement Sci. 2010;5(34):1-11.

62. Arnold HJ, Feldman DC. A multivariate analysis of the determinants of job turnover. J Appl Psychol. $1982 ; 67(3): 350-360$. 
63. Gustavsson JP, Hallsten L, Rudman A. Early career burnout among nurses: modelling a hypothesized process using an item response approach. Int J Nurs Stud. 2010;47(7): 864-875.

64. Laschinger HKS. Job and career satisfaction and turnover intentions of newly graduated nurses. J Nurs Manag. 2012;20(4):472-484.

65. Tomietto M, Rappagliosi CM, Sartori R, Battistelli A. Newcomer nurses' organisational socialisation and turnover intention during the first 2 years of employment. J Nurs Manag. 2015;23(7):851-858.

66. El-Jardali F, Dimassi H, Dumit N, Jamal D, Mouro G. A national cross-sectional study on nurses' intent to leave and job satisfaction in Lebanon: Implications for policy and practice. BMC Nurs. 2009;8(3):1-13.

67. Kingma M. Nursing migration: global treasure hunt or disaster in the making?. Nurs Inq. 2001;8:205-212.

68. McCarthy G, Tyrrell MP, Lehane E. Turnover rate in nursing and midwifery: The Irish experience. Nurs Times. 2003;8:249-263.

69. Blankertz LE, Robinson SE. Turnover intentions of community mental care workers in psychosocial rehabilitation services. Community Ment Health J. 1997;33:517-529.

70. Adams A, Bond S. Hospital nurses' job satisfaction, individual and organisational characteristics. J AdV Nurs. 2000;32(3):536-543.

71. Ho WH, Chang C, Shih YL, Liang RD. Effects of job rotation and role stress among nurses on job satisfaction and organizational commitment. BMC Health Serv Res. 2009;9(8):1-10.

72. Shader K, Broome ME, Broome CD, West ME, Nash M. Factors influencing satisfaction and anticipated turnover for nurses in an academic medical center. J Nurs Adm. 2001;31:210-216.

73. Camerino D, Conway PM, van der Heijden BIJ, EstrynBéhar M, Costa G, Hasselhorn HM. Age-dependent relationships between work ability, thinking of quitting the job, and actual leaving among Italian nurses: a longitudinal study. Int J Nurs Stud. 2008;45:1645-1659.

74. Cartledge S. Factors influencing the turnover of intensive care nurses. Intensive Crit Care Nurs. $2001 ; 17: 348-355$.

75. Derycke H, Clays E, Vlerick P, D'Hoore W, Hasselhorn HM, Braeckman L. Perceived work ability and turnover intentions: a prospective study among Belgian healthcare workers. J Adv Nurs. 2012;68:1556-1566.
76. Takase M, Nakayoshi Y, Teraoka S. Graduate nurses' perceptions of mismatches between themselves and their jobs and association with intent to leave employment: a longitudinal survey. Int J Nurs Stud. 2012;49:1521-1530.

77. Smith AC. Role ambiguity and role conflict in nurse case managers: An integrative review. Prof Case Manag. 2011;16:182-196.

78. Laschinger HKS, Finegan J. Using empowerment to build trust and respect in the workplace: A strategy for addressing the nursing shortage. Nurs Econ. 2005;23:613.

79. Peterson J, McGillis Hall L, O'Brien-Pallas L, Cockerill R. Job satisfaction and intentions to leave of new nurses. J Res Nurs, $2011 ; 16(6): 536-548$.

80. Choi SH, Jang IS, Park SM, Lee HY. Effects of organizational culture, self-leadership and empowerment on job satisfaction and turnover intention in general hospital nurses. J Korean Acad Nurs Adm. 2014;20:206-214.

81. Kim YI, Geun HG. Comparing organizational commitment, nursing organization culture, and job satisfaction of Korean Nurses working in Korea and the U.S. Korean J Occup Health Nurs. 2015;24:19-30.

82. Lee MS. Effect of duty satisfaction cause to the occupation change. In:Kyunghee University, Seoul, South Korea:2003.

83. Moreno-Jiménez B, Gálvez-Herrer M, RodríguezCarvajal R, Vergel AIS. A study of physicians' intention to quit: the role of burnout, commitment and difficult doctor-patient interactions. Psicothema. 2012;2:263270.

84. Van der Heijden BIJM, Van Dam K, Hasselhorn H-M. Intention to leave nursing: the importance of interpersonal work context, work-home interference and job satisfaction beyond the effect of occupational commitment. Career Dev Int. 2009; 14:1362-1436.

85. Adler PS, Kwon S-W. Social Capital: Prospects for a New Concept. Acad Manage Rev. 2002;27(1):17-40.

86. Ring SP, Van De Ven HA. Developmental process of coorperative interorganizational relations. Acad Manage Rev. 1994;19(1):90-118.

87. Al-Atwi AA. Oblivious, paranoid, and disclosed negative ties: An examination of the mechanisms underlying the relationship between negative ties and job performance. J Organ Behav. 2018;39(5):648-662. 
88. Marineau JE, Labianca GJ, Kane GC. Direct and indirect negative ties and individual performance. Soc Networks. 2016;44:238-252.

89. Csaba Z, Pál J. How negative networks are forming and changing in time? Theoretical overview and empirical analysis in two high-school classes. Rev Sociol. 2010;20(2):69-95.

90. Everett MG, Borgatti SP. Networks containing negative ties. Soc Networks. 2014;38: 111-120.

91. Harrigan NM, Labianca G, Agneessens F. Negative ties and signed graphs research: Stimulating research on dissociative forces in social networks. Soc Networks. 2020;60:1-10.

92. Burt SR. The contingent value of social capital. Adm Sci Q. 1997;42:339-365.

93. Burt SR. Structural Holes and Good Ideas. Am J Sociol. 2004; 110(2):349-399.

94. Burt SR. Brokerage \& Closure. New York, NY: Oxford University Press; 2005.

95. Berger J, Fisek M.H., Norman, R.Z., Zelditch, M. Status characteristics and social interaction: An expected states approach, New York, Elsevier, 1977.

96. Lerner J, Lomi A. Team diversity, polarization, and productivity in online peer production. Soc Netw Anal Min. 2019;9(29):1-17.

97. Luthans, F., Norman, S.M., Avolio, B.J. and Avey, J.B., The mediating role of psychological capital in the supportive organizational climate-employee performance relationship. J. Organiz. Behav., 2008, 29: 219-238

98. Brass DJ. Being in the right place: A structural analysis of individual influence in an organization. Adm Sci Q. 1984;29:518-539.

99. Krackhardt D. Assessing the political landscape: Structure, cognition, and power in organizations. Adm Sci Q. 1990;342-369.

100.Cammann C, Fichman M, Jenkins GDJr, Klesh JR. Assessing the attitudes and perceptions of organizational members. In: Seashore SE, Lawler EE, Mirvis PH, Cammann C. eds. Assessing Organizational Change: A Guide to Methods, Measures, and Practices New York, NY: Wiley; 1983.

101.Gurbuz S, Bekmezci M. The mediating and moderating role of affective commitment in the effect of human resource management practices on turnover intention of knowledge workers. Istanbul
University Journal of the School of Business Administration. 2012;41 (2);189-213.

102.Rahim A. A measure of styles of handling interpersonal conflict. Acad Manage J. 1983;26 (2):368-374

103. Kocaman S, Kocaman S, Cakir N. The effects of organizational culture on organizational conflict in accomodation establishments: A research in Alanya region. Journal of Social Sciences and Humanities Researches. 2012;(28):167-183.

104.Fornell C, Larcker DF. Evaluating structural equation models with unobservable variables and measurement error. J Mark Res. 1981;18(1):39-50.

105. Hair JFJr, Black WC, Babin BJ, Anderson RE, Tatham RL. Multivariate Data Analysis. Upper Saddle River, 6th ed. New Jersey, Pearson Education; 2006.

106. Hair JFJr, Black WC, Babin BJ, Anderson RE. Multivariate Data Analysis. Upper Saddle River, 7th ed. New Jersey, Pearson Education; 2014.

107. Henseler Jö, Ringle CM, Sarstedt M. A new criterion for assessing discriminant validity in variance-based structural equation modeling. J. Acad. Mark. Sci. 2015;1-21.

108.Baron RM, Kenny DA. The moderator-mediator variable distinction in social psychologicalresearch: Conceptual, strategic, and statistical con-siderations. J Pers Soc Psychol. 1986;51:1 173-1182.

109.Zhao X, Lynch JrJG, Chen Q. Reconsidering Baron and Kenny: Myths and truths about mediation analysis. J Consum Res. 2010;37(2):197-206.

110.Dogan D. SmartPLS ile veri analizi. US: Charleston SC; 2018. 